MENTAL IMAGERY AND HUMAN MEMORY 


\title{
MENTAL IMAGERY AND HUMAN MEMORY
}

\author{
JOHN T. E. RICHARDSON
}

Lecturer in Psychology, Brunel University

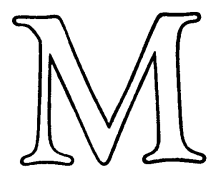


(C) John T. E. Richardson I980

Softcover reprint of the hardcover 1st edition 1980

All rights reserved. No part of this publication may be reproduced or transmitted, in any form or by any means, without permission

First published 1980 by

THE MACMILLAN PRESS LTD

London and Basingstoke

Associated companies in Delhi Dublin

Hong Kong Johannesburg Lagos Melbourne

New York Singapore and Tokyo

British Library Cataloguing in Publication Data

ISBN 978-1-349-16356-4 ISBN 978-1-349-16354-0 (eBook)

DOI 10.1007/978-1-349-16354-0

This book is sold subject to the standard conditions of the Net Book Agreement 
Dedicated to Sonia 


\section{Contents}

Preface $\quad$ ix

Introduction

2 Psychological Attitudes to Mental Imagery 4

2.1 The Rise of Behaviourist Psychology 4

2.2 Contemporary Psychological Accounts 6

2.3 Mental Imagery in Contemporary Psychology 8

2.4 Dual Coding Theory 13

2.5 Common Coding Theory $\quad$ I5

2.6 Conceptual Criticisms of Mental Imagery $\quad{ }_{16}$

2.7 Conclusions $\quad 22$

3 A Conceptual Analysis of Mental Imagery 25

3.I The Behaviourist Critique of Introspectionism 25

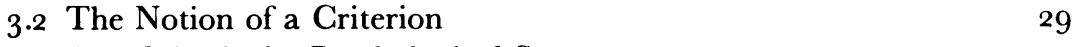

3.3 The Criteria for Psychological States 3 I

3.4 Imagery and Memory 33

3.5 The Intentionality of Mental Imagery $\quad 39$

3.6 Conclusions $\quad 4$ I

4 Mental Imagery in Immediate Memory 43

4.I The Representation of Spatial Information 44

4.2 The Manipulation of Spatial Information 45

$4 \cdot 3$ Mental Comparisons $\quad 46$

$4 \cdot 4$ Selective Interference $\quad 54$

$\begin{array}{ll}4 \cdot 5 \text { Conclusions } & 59\end{array}$

5 Pictorial Memory $\quad 60$

5.1 Memory for Pictures 6I

5.2 Faces: A Special Case? $\quad 64$

$\begin{array}{ll}5 \cdot 3 \text { Pictures and Words } & 65\end{array}$

$5 \cdot 4$ Pictures and Mental Imagery $\quad 67$

$\begin{array}{ll}5 \cdot 5 \text { Conclusions } & 69\end{array}$ 


\section{Imagery Mnemonic Instructions}

6.I The Effects of Imagery Instructions 71

6.2 Interactive and Separative Imagery 73

6.3 Imagery and Verbal Instructions $\quad 76$

6.4 Imagery Instructions and Selective Interference 78

6.5 The Usefulness of Imagery Mnemonics 80

$\begin{array}{ll}6.6 \text { Conclusions } & 82\end{array}$

7 Remembering Individual Words

7.I Stimulus Imageability $\quad 84$

7.2 Stimulus Concreteness 90

7.3 Lexical Complexity 93

7.4 Imageability and Mnemonic Instructions 94

7.5 Imageability and Selective Interference 97

$\begin{array}{ll}7.6 \text { Conclusions } & 99\end{array}$

8 Remembering Connected Narrative

8.I Memory for Phrases IOI

8.2 Memory for Sentences 103

8.3 Imagery, Meaning and Understanding Io9

8.4 Schemata and Thematic Structure II I

8.5 Conclusions 116

9 Individual Differences 117

9.I Introspective Questionnaires 1 I 8

9.2 Imagery Control $\quad 126$

9.3 Reported Mediators $\quad$ I 27

9.4 Spatial Ability 130

9.5 Coding Preference 133

9.6 Neuropsychological Evidence $\quad$ I34

9.7 Conclusions 141

Io Conclusions 143

$\begin{array}{ll}\text { References } & 148\end{array}$

Author Index $\quad$ I $7 \mathrm{I}$

$\begin{array}{ll}\text { Subject Index } & { }_{1} 76\end{array}$ 


\section{Preface}

Over the last eight years, I have carried out a variety of experimental investigations of the role of mental imagery in human memory. In common with many other research workers, I have found mental imagery to be a fascinating, yet extremely elusive phenomenon to study in the psychological laboratory. Under many circumstances, it is possible to demonstrate substantial empirical effects which may be attributed to the operation of mental imagery, as I shall explain in the central chapters of this book.

Be that as it may, our understanding of the significance of mental imagery for remembering in everyday life is still very limited. The obvious experiments, the easy, well-controlled studies of remembering under artificial conditions have now been done; the much more difficult problem of saying anything meaningful about the cognitive tasks which confront ordinary people in their everyday activities has yet to be faced. Nevertheless, the considerable amount of laboratory research which has been carried out to date may be seen as an important preliminary to the latter activity. In this book, I have tried to give a perspicuous summary of this research within a reasonable and reasoned theoretical context.

The experimentation on mental imagery has been heavily influenced by the behaviourist tradition in experimental psychology. To understand the research which has been carried out, it is necessary to understand that tradition, and to assess its conceptual adequacy as a scientific methodology for the investigation of personal experience. I hope that I have given a fair and balanced account of the behaviourist tradition, even though I believe its effects upon the development of cognitive psychology to have been largely detrimental. More generally, I hope that it will become clear to the reader that advances in human experimental psychology are likely to result from the combined use of empirical investigation and of conceptual analysis.

To the extent that this book is able to make any contribution to the development of our knowledge and understanding of the role of mental imagery in human memory, it is because I have been able to focus my training and research experience both in human experimental psychology and in philosophy. Accordingly, I am pleased to be able to acknowledge my gratitude to those who have been instrumental in determining such skills as I have in these areas. In particular, I would like to thank Alan Baddeley for his guidance and example 
when I began my research on mental imagery as a graduate student at the University of Sussex; Allan Paivio, for the inspiration of his writings, and for his continued encouragement of my own efforts; and Peter Hacker, for his patient instruction and specifically for his helpful advice on the conceptual problems discussed in this book. I am also grateful to my colleagues and students at Brunel University for their various reactions to my ideas over the last four years. Finally, I would like to thank my wife, Sonia, for her patience and tolerance during the months in which this book has been written, and for her careful reading of the final draft.

Department of Psychology

John T. E. Richardson

Brunel University

Uxbridge, Middlesex

April 1979 